\title{
FISCAL AND MONETARY POLICY, UNFORTUNATE EVENTS, AND THE SGP ARITHMETICS Evidence from a growth-gap model
}

\author{
Edoardo Gaffeo \\ Giuliana Passamani \\ Roberto Tamborini
}


The Discussion Paper series provides a means for circulating preliminary research results by staff of or visitors to the Department. Its purpose is to stimulate discussion prior to the publication of papers.

Requests for copies of Discussion Papers and address changes should be sent to:

Dott. Stefano Comino

Dipartimento di Economia

Università degli Studi

Via Inama 5

38100 TRENTO ITALY 


\title{
Fiscal and monetary policy, unfortunate events, and the SGP arithmetics
}

\author{
Evidence from a growth-gaps model*
}

\author{
Edoardo Gaffeo
}

Giuliana Passamani

Roberto Tamborini

Department of Economics, University of Trento

46a Riunione Scientifica Annuale della Società Italiana degli Economisti, Napoli, 21-22 Ottobre 2005

\begin{abstract}
The recent revision (March 2005) of the Stability and Growth Pact (SGP) has confirmed the $3 \%$ deficit/GDP ratio as the pillar of the excessive deficits procedure envisaged by the Maastricht Treaty for member countries of the EMU. Since the deficit/GDP ceiling is still in place, research on its implications for fiscal discipline and macroeconomic stabilization has to be pushed further. We argue that the agenda largely involves empirical matters. In particular, this paper presents an econometric estimate and simulations of a macroeconomic model of Italy and Germany aimed at addressing three issues. First, monetary and fiscal rules intercations are explictly modelled and examined in dynamic setting. Second, consistently with common perception and the new formulation of the SGP, the business cycle and the responses of policy variables are cast in terms of growth gaps, not gaps in levels, with respect to potential. Third, budgetary components (primary expenditure and total tax revenue) are examined as separate fiscal rules, which allows us to track the reaction of the fiscal stance to growth shocks more precisely, to point out several pitfalls in current measures of fiscal ratios to GDP, and suggest more accurate assessment of fiscal stances.
\end{abstract}

JEL Classification: E0; E6

Keywords: Fiscal policy; Stability and Growth Pact.

* We thank, for useful comments and discussions, Jacques Melitz, Francesco Farina, Patrizio Tirelli, the participants in the Second Lectures on Macroeconomic Governance in EMU at the University of Siena, May 2005, and in the 46th Meeting of the Italian Economists Society, Naples, October 2005. 

"[...] since the second half of 2004, growth in the Euro area has been modest, below the area's potential growth rate"

Jean-Claude Trichet (May 30 ${ }^{\text {th }}, 2005$ )

"[...] the delivery of the new, refocused Lisbon agenda could boost Europe's natural rate of growth to around 3 percent per year and bring our goal of full employment within reach by the end of the decade"

José-Manuel Barroso (April 2 ${ }^{\text {nd }}, 2005$ )

\section{Introduction}

The recent revision (March 2005) of the Stability and Growth Pact (SGP) has confirmed the $3 \%$ deficit/GDP ratio as the pillar of the "excessive deficits procedure" envisaged by the Maastricht Treaty for member countries of the EMU. The many criticisms levelled time and again precisely against the misconception of the deficit/GDP ceiling as a means to measure excessive deficits in the Maastricht Treaty's spirit have only marked a limited succes in that some more "flexibility" has been injected into the procedure, by allowing deduction of a list of long-run growthpromoting expenses, a longer time span for correction of excess deficits, and less stringent definition of "recession" to qualify for exemption from the excess deficit procedure 1 . Since the deficit/GDP ceiling is still in place research on its implications for fiscal discipline and macroeconomic stabilization has to be pushed further. We argue that the agenda largely involves empirical matters. In particular, this paper presents an econometric exercise aimed at addressing the following issues.

First, analyses and prescriptions concerning fiscal and monetary policy in a monetary union should be rooted in a fully specified macroeconomic scenario in which the interactions between the two policies are clearly understood and identified. Favero (2002) recalls the theoretical reasons that underpin this claim and shows the empirical mistakes that may be generated by piece-wise analyses of monetary and fiscal policies.

1 These new caveats and exemptions add to others, previoulsy introduced - most notably the introduction of official measures of "recessions" allowing for exemptions and of "cyclically adjusted" deficit/GDP ratios. See Buti and Sapir (1998), Galì and Perotti (2003), Buti and Franco. (2005) for a brief account of these progressive adjustments. 
Developments in this direction are only recent (e.g. Melitz (2002), Muscatelli et al. (2004), Farina and Ricciuti (2005)). By contrast, most of the empirical work that has been produced so far in support of the SGP approach does not meet this requirement. This holds true both for works aimed at showing the tendency of pre-Maastricht European governments towards "fiscal indiscipline" (see e.g. Buti and Sapir (1998, Ch.VII)), and for research aimed at showing the adequacy of domestic stabilizers within the SGP limits (see e.g. Buti et al. (1998), Artis and Buti (2000))2.

Second, it is well-known that the deficit/GDP ratio is a variable highly sensitive to the business cycle, if anything because both the numerator and the denominator are cyclical. Nonetheless, most applied research still uses the deficit/GDP ratio as a single variable. However, the official methods to identify the cyclical component of the total budget are far from satisfactory. As shown by Melitz (2005), the current practice that starts from the total deficit and proceeds by correcting for selected cyclical stabilizers may miss the target quite easily. Selection of candidate items based on ex-ante institutional information (see e.g. Perotti (2002)) soon enters a tangle of norms and practices wildly different from country to country ${ }^{3}$. The textbook antinomy between "cyclical budget/automatic stabilizers" on the one hand, and "structural budget/discretionary interventions" on the other, is misleading in practice. Stabilization policy may be realized by means of discretionary measures, and these measures may also have structural effects. As a matter of example, think of a cut of distortionary taxes during a recession (Galì and Perotti, 2003). We argue that new effort is necessary to trace the cyclical behaviour of deficit/GDP ratio back to its two components, especially as "excessive deficits" measures and procedures are to be based on a clear identification (and delimitation) of governments' responsibilities.

Moving in this perspective, a third issue at stake is that budget analysis by components should be pushed further. The decomposition between primary and total budget is a minimal requirement, since over the typical time horizon of the business cycle interest payments are largely predetermined by the stock of outstanding debt and by the effect of monetary policy on interest rates. Thus, a reasonable approximation to the

2 Preliminary work that address this issue can be found in Farina and Tamborini (2002, 2004), Tamborini (2004)

3 And the estimates of "fiscal shocks" obtained by Perotti are by his own admission not very plausible in several instances. 
actual fiscal stance of the government would at least require a good measure of the cyclically-adjusted primary budget. To this effect, we should consider that existing evidence suggests that primary expenditure on the one hand, and total tax revenue on the other may have different cyclical properties (e.g. Favero (2002), Galì and Perotti (2003), Melitz (2005)) .

Finally, issues concerning the correct measurement of the cyclical position of a country and the response of its fiscal variables should be reconsidered carefully. To some extent this need is recognized in the reformulation of exemption clauses in the new SGP. Old exemptions of the $3 \%$ rule based on the increasing "gravity of recessions" were complex and too strict. All included negative growth rates of GDP (from less than $-0.75 \%$ ("mild") to more than - 2\% ("exceptional")). Buti and Sapir (1998) have detected just 84 observations in this range for all EU countries (5 for Italy, 8 for Germany) from 1961 to 1997. However, the words of the Presidents of the the European Central Bank and of the European Commission quoted above $^{4}$ represent anedoctical evidence supporting what seems to be an uncontroversial fact. When thinking of macroeconomic performance and how it can be influenced through policy actions, policymakers think in terms of differences between actual and potential GDP growth rates (growth gap), and to them a downturn starts whenever the observed growth rate is negative relative to the trend (potential) rate even though positive in absolute terms. Accordingly,

"a breach of the threshold [of 3\% deficit] will now be considered exceptional if it results from a negative growth rate or an accumulated loss of output during a protracted period of very low growth relative to potential growth" (Buti and Franco (2005, p.15), italics added).

Given that the focus of the new normative macroeconomics (Taylor, 1999) on policy rules is aimed at assessing how policymakers do and should behave in practice, why is it that the bias of central bankers and prime ministers for percentage points is seldom considered in theoretical and empirical models?

The materials that we present in this paper are organized as follows. In section 2 we introduce a macroeconomic model with monetary and fiscal

4 Respectively available at http:/www.bis.org/review/r050602d.pdf and at http://www.eua.be/eua/jsp/en/upload/Barroso_speech.1112693429657.pdf. 
policy rules suitable to econometric estimation. The model includes aggregate demand and supply for GDP and the inflation rate, a Taylor rule for the nominal interest rate and two fiscal rules for primary expenditure and total tax revenue. Two features are noteworthy. The first is that the model is specified so as to capture cycles in terms of gaps in growth rates rather than in levels of GDP. Consequently we have a system of linear dynamic equations whereby we can study the evolution of the endogenous variables over the cycle in terms of rates of deviation from their balanced or target growth paths. The second feature is that the monetary and fiscal rules are interdependent. Section 3 reports on the econometric results for Italy and Germany with yearly data from 1962 to 2004 . We have chosen these two countries not only because they are major euro-economies, but especially because they differ markedly as to their monetary and fiscal history. Hence we expected that their comparison might deliver rich information on the issue of fiscal-monetary interactions, and econometric results do lend support to this presumption. Section 4 presents simulations of a temporary negative shock to the GDP growth rate in the two economies based on the respective estimated models. Simulations concern the five endogenous variables as well as two additional variables derived from the previous ones, namely the primary and the total budget. As explained above, the system yields the sequence of variations of the variables until a new steady-state is reached and conveys information on the different dynamics of the various budget components over the cycle. From these simulated data, we can also examine the evolution of the deficit/GDP ratio sheding light on the much debated question of the actual control of governments on its cyclical behaviour. Section 5 presents some concluding remarks.

\section{A "growth gaps" model for studying fiscal and monetary policy interactions}

Our analysis is based on a theoretical framework rooted in the New Keynesian approach, whose main target is to determine output, temporary rigid nominal prices and the interest rate exploiting general-equilibrium interactions in the simplest possible way (Krugman, 2000). Following e.g. Bean (1998), Cecchetti (2000) and Taylor (2000a), such a model should rest on three main ingredients: a) an $\mathrm{AD}$ curve relating current real spending 
and the real interest rate; b) an AS curve which relates prices and output, such that the relationship is vertical in the long-run and positively sloped in the short-run; c) one (or more) policy reaction function(s) (RF), which illustrates how policymakers react to shocks. This class of models rests on the existence of a set of mutually consistent values of macro-variables that define the steady-state general equilibrium of the system where output is at its potential level. Then, policy analysis is cast in terms of deviations from the steady state.

\subsection{The core model of practical macroeconomics ${ }^{5}$}

In its basic form, the theoretical framework used for empirical policy analysis has the following typical format 6

$$
\begin{aligned}
(\mathrm{AD}): & \hat{y}=\alpha-\beta r+\gamma z+u_{y} \\
(\mathrm{AS}): & \hat{\pi}=\phi \hat{y}+u_{\pi} \\
(\mathrm{MRF}): & i=\pi+r^{*}+\varepsilon \hat{\pi}+\delta \hat{y}+u_{i} \\
(\mathrm{FRF}): & z=z^{*}+\eta \hat{y}+u_{z}
\end{aligned}
$$

Real variables are defined in logarithm $(x=\ln (X))$, while $(\wedge)$ denotes the contemporaneous deviation of a variable from its steady-state or its target value $\left(\hat{x} \equiv x-x^{*}\right)$. Equation (1) states that deviations of actual output from its potential $\hat{y}$ depend on the real interest rate $r$, on a variable measuring fiscal stance $z$, and on a real shock $u_{y}$. The variable $z$ may be a measure of expenditure, of taxation or of the overall government budget depending on different specifications and microfoundations of the model. The parameter $\gamma$ can be positive or negative depending on the fiscal variable chosen. By

\footnotetext{
5 Terminology is due to AEA (1997).

6 A similar framework may be derived from a rigorously microfounded dynamic general equilibrium model (e.g. McCallum and Nelson (1999) among many others), where the relations corresponding to our equations (1) and (2) are derived from households choosing optimal intertemporal paths for their consumption and firms setting prices optimally according to a Calvo-type mechanism. The main difference with the specification we employ is that explicit microfoundations allow expectations on future output and inflation to explicitly appear in the IS and the Phillips curves, respectively. Useful surveys of the so-called New IS-LM model are Clarida et al. (1999) and King (2000).
} 
imposing the steady-state condition $\hat{y}=0$, from (1) we obtain the neutral real interest rate as: ${ }^{7}$

$$
r^{*}=\frac{\alpha}{\beta}+\frac{\gamma}{\beta} z^{*},
$$

that is the real interest rate consistent with output equalling its potential level at constant inflation. Notice that the neutral interest rate is a function of the steady-state, or structural, fiscal stance. Making use of (5), and defining $r \equiv r^{*}+\hat{r}, z \equiv z^{*}+\hat{z}$, equation (1) may be rewritten as:

$$
\hat{y}=-\beta \hat{r}+\gamma \hat{z}+u_{y} .
$$

Equation (2) is a simple AS curve, saying that inflation grows higher than the official target chosen by the Central Bank $\left(\hat{\pi}=\pi-\pi^{*}>0\right)$ as soon as the output gap and the inflation shock $u_{\pi}$ are positive. The parameter $\phi>$ 0 measures the flexibility of prices: the higher is $\phi$, the faster is the adjustment of prices towards their market-clearing level. Temporary deviations of output from its potential imply a positively sloped relation between inflation and output, while non-zero realizations of the inflation shock when output is at its potential cause shifts of the inflation rate along a vertical (long-run) relation. Note that this specification is consistent with an expectations-augmented AS, where the expected inflation rate is moved to the left-hand side and is assumed to be equal the central-bank target $\pi^{* 8}$. This implies that inflation is always near its target.

Equation (3) represents a general parameterization of the well-known Taylor's rule for monetary policy (Taylor, 1993), with the term $u_{i}$ representing a monetary shock. The main idea is that the central bank sets the short-run nominal interest rate $(i)$ in order to target the neutral interest rate. Deviations of actual inflation from its target level and of the actual output from its potential are associated with a deviation of the real interest rate from its neutral level of the same sign. As discussed in Allsopp and

7 In spite of resembling very closely the Wicksellian notion of natural real rate of interest, $\mathrm{r}^{*}$ is directly influenced by fiscal policy so that the term neutral is more suitable (Allsopp and Vines, 2000). In fact, standard economic theory implies that the neutral rate of interest is a function of consumers' preferences and of the trend growth rate of output. If an endogenous growth mechanism is added to the model, fiscal policy may affect the neutral rate of interest even in a Wicksellian world via its impact on the steady-state growth rate. Note, however, that the channel involved here is quite different.

8 See Cecchetti (2000). 
Vines (2000), a monetary authority endowed with a rule like (3) can successfully deal with the two main functions usually assigned to monetary policy, that is to provide a nominal anchor to the economy and to stabilize output fluctuations.

Equation (4) is the policy rule of the fiscal authority, and represents a more recent extension of the framework towards fiscal policy analysis (Taylor (2000a)). Typically, the fiscal variable is conceived of as sensitive to the business cycle, so that it remains at its steady-state value $z^{*}$ up to deviations in output or exogenous fiscal shocks $\left(z^{*}=0\right.$ in case $z$ represents the overall budget).

\subsection{The "growth gaps" model}

Among recent studies of monetary-policy interactions in the EMU one may find Favero (2002) and Melitz (2002) as examples of empirical structural models, and Muscatelli et al. (2004) as an example of microfounded structural model, all yielding specifications of the previous reference framework. The change of perspective in order to account for the attitude of policy-makers to think in terms of gaps in growth rather than of gaps in levels may be addressed straightforwardly within that framework.

By construction, the model (1-bis)-(4) is fully consistent with a balanced-growth solution, such that at every point in time the output level $Y_{t}$ equals its potential, $Y^{*}$, which in turn is assumed to grow over time by the constant potential growth rate $q^{*}$, i.e. $Y_{t}^{*} / Y^{*}{ }_{t-1}=1+q^{*}$, all $t$. Hence, along such a growing path:

- the inflation rate is constant and equal to the target value set by the central bank, $\pi^{*}$;

- the nominal and real interest rates are constant and fulfill the Fisher equation, $i^{*}=r^{*}+\pi^{*}$;

- to have a constant real interest rate, all real asset stocks should be on a balanced growth path with GDP, which for public debt, in real terms, implies $D^{*}{ }_{t} / D^{*}{ }_{t-1}=1+q^{*}$, all $t$ (i.e. a constant real debt/GDP ratio, $D^{*}{ }_{t} / Y^{*}{ }_{t}=d^{*}$, all $\left.t\right)$;

- consequently, real interest payments, $I P_{t}=r^{*} D_{t-1}$, also grow at the GDP rate, $I P^{*}{ }_{t} / I P^{*}{ }_{t-1}=1+q^{*}$ (i.e. they are constant as a ratio to GDP, $\left.I P^{*}{ }_{t} / Y^{*}{ }_{t}=r^{*} d^{*}\right)$; 
- the government budget, in real terms, must satisfy the condition $B^{*}{ }_{t}=$ $-q^{*} D_{t-1}^{*}$, which implies a target value for the primary balance such that $P B^{*}{ }_{t}=-q^{*} D^{*}{ }_{t-1}+I P_{t}{ }_{t}$; as a consequence, $P B^{*}{ }_{t} / P B^{*}{ }_{t-1}=1+q^{*}$ (i.e. both the total and the primary balance/GDP ratios are constant, $B^{*}{ }_{t} / Y^{*}{ }_{t}=$ $\left.-d * \frac{q^{*}}{1+q^{*}}, P B^{*}{ }_{t} / Y^{*}{ }_{t}=d * \frac{r^{*}-q^{*}}{1+q^{*}}\right)$;

- a sufficient condition for targets on primary expenditure $G^{*}{ }_{t}$ and total tax revenue $T^{*}{ }_{t}$ to satisfy the primary balance constraint is that $G^{*}{ }_{t} / G^{*}{ }_{t-1}=T^{*}{ }_{t} / T^{*}{ }_{t-1}=1+q^{*}$ (i.e. constant ratios to GDP);

It is well-known that the SGP arithmetics is consistent with this reference state as long as $q^{*}=3 \%, \pi^{*}=2 \%$, and $d^{*}=60 \%$, which yield a target deficit/GDP ratio of $5 \%$ in nominal terms. The target primary budget/GDP ratio can be close to balance on the "classical" assumption that $r^{*}=q^{*}$. The recommendation that the target total budget be "close to balance or in surplus" implies a positive target primary balance, and a reduction of any non-zero debt/GDP ratio, along the GDP potential path.

Now let $q_{t}$ be the actual growth rate of a variable $x_{t}$ in logs, i.e. $q_{t}=x_{t}$ $-x_{t-1,1}$ and $q^{*_{t}}=x^{*}{ }_{t}-x^{*}{ }_{t-1}$ its target growth rate. Clearly, the growth gap of $x_{t}$ is given by $q_{t}-q^{*}{ }_{t}=\Delta x_{t}-\Delta x^{*}{ }_{t}=\hat{x}_{t}-\hat{x}_{t-1}=\Delta \hat{x}_{t}$. Thus, the system (1-bis)-(4) has to be transformed in order to get the rates of change, i.e. the time first differences, of the left-hand-side variables. This specification gives prominence to the time structure - "leads and lags" - of the estimation model. The underlying theoretical model presented in the previous paragraph is too simple to give guidance. But economic theory in general does not deliver univocal results concerning the time structure of dynamic models. Dynamic stochastic general equilibrium models stress the role of rational forward-looking behaviour such that expected future variables determine current ones. However, they deny the relevance of, or are mute about, the role of lagged variables which by contrast are largely used in econometric practice. Agnostically, one might put the model under test in a general dynamic form, whereby all endogenous and exogenous variables enter with current and lagged values, and "let the data say" what the best time structure is, in the spirit of the "general-to-specific" approach. It follows that, given the theoretical structure provided by model (1-bis)-(4), the general system we have deployed for estimation is: 


$$
\begin{aligned}
\Delta \hat{y}_{t}= & c_{10}+C_{11}(L) \Delta \hat{y}_{t-1}+C_{12}(L) \Delta \hat{r}_{t}+C_{13}(L) \Delta \hat{g}_{t}+C_{14}(L) \Delta \hat{\tau}_{t}+ \\
& +C_{15}(L) z_{1 t}+u_{1 t} \\
\Delta \hat{\pi}_{t}= & c_{20}+C_{21}(L) \Delta \hat{\pi}_{t-1}+C_{22}(L) \Delta \hat{y}_{t}+C_{23}(L) z_{2 t}+u_{2 t} \\
\Delta i_{t}= & c_{30}+C_{31}(L) \Delta i_{t-1}+C_{32}(L) \Delta \pi_{t}+C_{33}(L) \Delta \hat{\pi}_{t}+C_{34}(L) \Delta \hat{y}_{t}+ \\
& +C_{35}(L) z_{3 t}+u_{3 t} \\
\Delta \hat{g}_{t}= & c_{40}+C_{41}(L) \Delta \hat{g}_{t-1}+C_{42}(L) \Delta \hat{y}_{t}+C_{43}(L) z_{4 t}+u_{4 t} \\
\Delta \hat{\tau}_{t}= & c_{50}+C_{51}(L) \Delta \hat{\tau}_{t-1}+C_{52}(L) \Delta \hat{y}_{t}+C_{53}(L) z_{5 t}+u_{5 t}
\end{aligned}
$$

where $\Delta$ is the time first-difference operator, $C_{i j}(\mathrm{~L})$ are polynomial of coefficients in the time-lag operator $L, g_{t}$ is the log of the real primary public expenditure at time $t, \tau_{t}$ is the log of the real total tax revenue, $r_{t}=i_{t}-\pi_{t+1}$ is the one-year real interest rate, $z_{i t}$ are exogenous variables to be specified below, and finally $u_{i t}$ are stochastic shocks with the usual properties.

The estimation model (7)-(11) differs from (1-bis)-(4) with respect to a few important features. First of all, let us draw attention to the correct interpretation of this model. It aims at representing an economy in which all real variables and prices grow over time. In steady-state, each variable grows along its balanced growth path as explained above. The reader can easly check that as the vectors of shocks $\mathrm{u}_{t}$ and of exogenous variables $\mathrm{z}_{t}$ are null, so is the vector of the endogenous variables $\mathrm{v}_{t}=\left[\Delta \hat{y}_{t}, \Delta \hat{\pi}_{t}, \Delta i_{t}\right.$, $\Delta \hat{g}_{t}, \Delta \hat{\tau}_{t}$ ], meaning that all real variables and prices lie on their steady-state growth path while the nominal interest rate is constant at its target value $i$ * $=r^{*}+\pi^{*}$.

The problem of interest is the system's dynamic response when one or more variables are shocked and display positive or negative growth gaps. A crucial part of the problem is how the policy variables react in the presence of undesired growth gaps in the relevant variables. The policy-relevant growth gaps are those in real GDP (for both policy arms) and in the inflation rate (for the monetary arm). GDP growth gaps are expressed by equation (7), which is derived by first differencing equation (1-bis) after splitting the fiscal stance into the two primitive components of real primary expenditure and real tax revenue (see also below). Inflation growth gaps are expressed by equation (8), which is in turn the first difference of equation (2), that is its "accelerationist" version which measures by how much the inflation rate accelerates above, or decelerates below, the target rate.

The policy reaction functions constitute the second noteworthy characteristic of our model. These are given by equations (9) to (11), 
whereby the monetary variable is moved above or below its target level, whereas the two fiscal variables react by growing more or less than their target rate. The monetary policy equation (9) is just the "accelerationist" version of the standard Taylor rule (3) consistent with the "accelerationist" equation for inflation (8). With respect to equation (4), fiscal policy is represented by two separate symmetric fiscal reaction functions, one for real primary public expenditure (10) and the other for real total tax revenue (11). This allows us to study the cyclical and non-cyclical components for each fiscal variable separetely as emerging in the recent theoretical and empirical literature on fiscal rules (e.g. Perotti (2002), Galì and Perotti (2003), Favero (2002), Melitz (2005)). Moreover, contrary to common practice both in theoretical and empirical models, fiscal policy rules are here measured in absolute real terms instead of ratios to GDP. As stressed by Melitz (2005) the two specifications yield different empirical results and lead to different policy implications. In particular, the coefficients of our fiscal policy equations estimate the exact elasticity of each real fiscal variable to growth gaps (not merely to output gaps), whereas the cyclical elasticity of total budget can correctly be derived by compounding the partial elasticities of each component. Thanks to this estimation of the elasticities of primitive fiscal variables, also the notorious pitfall of fiscal ratios to GDP, which stir the cyclical components of the numerator and of the denominator, can easily be corrected gaining important information as will be seen by means of simulations.

\subsection{The empirical strategy}

The general dynamic structural model (7)-(11) sets the stage for an econometric exercise aimed at comparing the experiences of Italy and Germany. In view of estimation, a few thorny problems had to be addressed. The first problem to be discussed concerns the assumption of structural stability underlying any econometric exercise. As is well known, this issue is particularly delicate when behaviour of institutions is involved, especially in view of extrapolations across institutional regimes ${ }^{9}$. We are aware of the number of institutional events that occured in the time period covered by our data set. The most important to be taken into account are the end of the

9 Alas, the caution necessary on this ground is seldom practiced. For instance, many tests of the feasibility of the SGP constraints were based on evidence of past performances of EU countries under completely different insitutional regimes. 
Bretton Woods exchange-rates system (1971), participation in the European Monetary System (1979-98 for Germany; 1980-92, 1996-98 for Italy), national reunification of Germany (1989), endorsement of the Maastricht Treaty's criteria for admission to EMU (1992) and subsequently of the SGP (1996), inception of EMU (1999). All these events are major candidates of structural changes in the data generating process, especially as regards policy variables. As a first step, a priori information on institutional events has been introdcued by means of dummy variables; the dummies that have proved to be significant or that have altered the quality of estatimates significantly are reported with the results below. Of course, we do not conclude that the events which are not associated with these selected dummies are irrelevant; simply, we leave the matter for further and more rigorous investigation.

A few more words of clarification are perhaps needed in relation to the most radical event, that is EMU, with the undisputable consequence that the two independent national institutions responsible for monetary policy as described by equation (9) have been substituted by the ECB. Unfortunately, the very small number of yearly observations available in the EMU period prevents reliable statistical analysis of either a structural break in the monetary policy equation of the two countries or estimation of an independent equation. In the face of the trade-off between curtailing the sample period in 1998 and loosing observations and degrees of freedom on the one hand, and including the EMU sub-period with a likely structural break on the other, we have opted for the second choice. Hopefully, the small number of observations may also limit the statistical relevance of this break $^{10}$.

Historical and institutional considerations have instead led us to envisage country-specific formats of the monetary policy variables. The standard Taylor rule (3), on which our "accelerationist" version (9) is based, can hardly be applied straightforwardly to our specific cases. The Taylor rule has been conceived with reference to a "large", independent, almost

10 On the other hand, the literature on the ECB points out that major central banks in Europe had long pursued converging frames and practices of policy conduct in view of the creation of the single central bank. And that the latter has indeed mostly endorsed and codified this heritage from predecessors, in particular from the Bundesbank (see e.g. Dornbush et al. (1998), Begg et al. (1999), and for the Bank of Italy Angeloni (1994)). 
"closed" economy where the central bank can freely set and pursue its own targets. As regards Italy, none of these preconditions was ever true. First, over a considerable part of the sample period (1962-71; 1980-92, 1996-98), Italy was part of exchange-rate agreements (Bretton Woods and the European Monetary System, respectively) which limited her central bank's ability to manage an independent monetary policy. Second, it is known that the Bank of Italy did not adopt explicit inflation targeting policy until the second half of the 1980s, though it can be argued that an exchange-rate target implies a target on domestic inflation vis-à-vis major trading partners (Visco (1995)). Thus, we have first considered a specification of equation (9) on the hypothesis that the Bank of Italy had an implicit target given by the German inflation rate until 1998, to be subsequently substituted by the inflation target officially set by the $\mathrm{ECB}^{11}$, i.e.

$$
\Delta \hat{\pi}_{t}^{I T A}=\left\{\begin{array}{c}
\Delta \pi_{t}^{I T A}-\Delta \pi_{t}^{G E R} t=1962-98 \\
\Delta \pi_{t}^{I T A} t=1999-04
\end{array}\right.
$$

As an alternative, we have also tried a more radical re-specification of equation (9) in consideration of the interest-rate parity constraint that an open economy within exchange-rate agreements like Italy had to face most of the time between 1962 and 1998. True, this constraint was not always equally strong and binding. In the Bretton Woods era low and controlled capital mobility allowed substantial room for domestic monetary policy. By contrast, according to well-established interpretations, monetary policy of non-German member countries in the EMS was severely constrained by interest-rate parity vis-à-vis Germany, and anti-inflationary monetary policy was mainly run not by chosing the domestic inflation target but by anchoring the domestic nominal interest rate to the German one (Visco (1995), Giavazzi and Pagano (1988)). Accordingly, the domestic inflation components, $\Delta \pi_{t}$ and $\Delta \hat{\pi}_{t}$, in equation (9) should be replaced by the interestrate parity constraint with Germany,

$$
i_{t} G E R+\mathrm{E}_{t}\left(\Delta e_{t}\right)
$$

where $\mathrm{E}_{t}$ is the expectation operator, $e_{t}$ is the log of the nominal lira-DM exchange rate and $\Delta e_{t}>0$ is the lira depreciation rate. Assuming that the

11 The ECB target has since been left unchanged at $2 \%$. As a consequence of a constant target, our "accelerationist" specification implies that the inflationtargeting variableis just equal to observed acceleration in the inflation rate, therefore $\Delta \hat{\pi}_{t}^{I T A}$ reduces to $\Delta \pi_{t}^{I T A}$. 
latter is determined by the inflation differential, and taking the first difference of the previous expression we obtain

$$
\Delta i_{t}^{G E R}+\Delta \hat{\pi}_{t}^{I T A}
$$

That is to say, changes in the Italian interest rate should be explained by changes in the German rate and/or in the inflation differential with Germany. On the other hand, the interest-parity constraint may be made consistent with the remaining part of equation (9) since the presence of factors relaxing the constraint (e.g. capital controls, fluctuation bands of the exchange rate, realignments, etc) allows domestic growth targeting to some extent. In consideration of the historically strong commercial and financial ties between Italy and Germany, we have tested the version of equation (9) corrected for the interest-parity constraint for the whole sample period. To account for major institutional events in the sample period, however, two dummies have also been added for 1980 (participation in the EMS) and 1992 (breakdown of the EMS parity).

As regards Germany, too, we have considered two possible specifications of the inflation-targeting component of equation (9). The first assumes that the inflation target may be variable over time; hence this has required a historical reconstruction of the official inflation target of the Bundesbank (as provided e.g. by Geberding et al. (2004)). The second follows the widely held belief that the ECB has substantially reproduced the monetary policy framework of the Bundesbank, which amounts to imposing that the inflation target for Germany has constantly been equal to $2 \%$.

$$
\Delta \hat{\pi}_{t}^{G E R}=\left\{\begin{array}{l}
\Delta \pi_{t}^{G E R}-\Delta \pi_{t}^{* G E R} \\
\Delta \pi_{t}^{G E R}
\end{array}\right.
$$

It should be noted, however, that according to the available reconstruction, the official inflation target of the Bundesbank, though not always equal to $2 \%$ until 1987, was rarely changed. Therefore, the two specifications of $\Delta \hat{\pi}_{t}^{G E R}$ produce two time series almost coincident with the actual change in the inflation rate. According to widely shared a priori information, we have also added a dummy variable for the post-reunification shock dated at 1991.

In the third place, the general dynamic format (7)-(11) of the model is open to further specifications and restrictions regarding exogenous variables $z_{i t}$ as well as the model's time structure. To begin with exogenous variables, we have aimed at a parsimonious selection first on theoretical and then on empirical grounds. Since our main theoretical interest is in policy variables, 
we have sought to enrich their respective specifications with particular attention to the channels through which fiscal-monetary policy interactions operate. These cannot be limited to the general-equilibrium feedbacks usually considered in the policy-mix literature. ${ }^{12}$ Interdependences between fiscal and monetary policies are likely to materialize also directly, in that instruments controlled by the monetary authority enter as right-handvariables into the the policy rule of the fiscal authority, and vice-versa.

Consider first the monetary policy equation (9) and the underlying standard Taylor rule (3) with the "real anchor" of the nominal interest rate in the neutral real interest rate $r^{*}$. In the light of equation (5), which relates $r^{*}$ to the structural fiscal stance, we have specified equation (9) to control for the possibility that the central bank tracks the dynamics of $r^{*}$ by means of the deviation-from-target of the public debt's rate of change. ${ }^{13}$ Hence,

$$
z_{3 t}=\Delta \hat{b}_{t}
$$

where $b_{t}$ is ratio of the current public deficit to the previous year's stock of debt.

As to the fiscal rules, we have followed Favero's (2002) specification, where the most important feed-back channel from monetary to fiscal policy is seen in interest payments. Given outstanding debt, changes in the interest rate impinge on current interest payments directly. This variable also relates to another issue in fiscal policy rules and the SGP debate, that is "budget smoothing": the fiscal authority is assumed to respond to changes in the deviation-from-target of interest payments by adjusting the primary balance according to the total budget target. Therefore, we have chosen

$$
z_{4 t}=z_{5 t}=\Delta \hat{I} P_{t}
$$

where $I P_{t}$ measures real interest payments. Non-null estimates of the relevant parameters, by controlling for the existence of budget smoothing, would provide evidence for a direct feedback from monetary to fiscal policy.

We have also considered that both Italy and Germany are highly open economies, and we have thought it wise to control their GDP growth gaps

12 See, inter alia, Leith and Wren-Lewis (2000) and Benigno and Woodford (2003) for DGE New-Keynesian models, Dixit and Lambertini (2001) for a game-theoretic approach, and Muscatelli et al. (2004) for empirical estimations.

13 The problem of a time-varying real anchor of the nominal interest rate in the Taylor rule is throughly discussed by Woodford (2003). The choice of the rate of change of public debt instead of the public deficit as a proxy for the neutral real rate of interest can be justified by recalling that in a complete general-equilibrium framework $\mathrm{r}^{*}$ should be also consistent with capital market equilibrium. 
for worldwide cyclical factors that we have proxied with the US growth gap, i.e.

$$
z_{1 t}=\Delta \hat{y}_{t}^{U S}
$$

Finally, there comes the specification of steady-state and target variables that are needed to compute our deviation variables. Though not free from faults, the only generally accepted and officially certified variable in this category is the year potential GDP. The other target variables present in our model are ususally matter of conjectures or separate estimates by indepedent researchers. This circumstance is unfortunate since it introduces hidden joint hypotheses and spurious variables in the statistical analysis of the model, the more so the more sofisticated is the separate estimate of the target variable(s). The problem is particularly serious for fiscal variables. The SGP targets are of little help for our study. First, because they were not in place for a long part of the time span of our database, even allowing for anticipation of the new rules as early as 1992. Second, because they are aggregate targets, whereas we wish to study the disaggregate components of the government budget. Further, available empirical results about fiscal target variables are less developed and more controversial than in the case of monetary ones. The official statistics closest to our theoretical variables are the so-called "structural" or "cyclically adjusted" fiscal items and balances released by national and international institutions. These are, however, far from satisfactory since they are fraught with arbitrariness in the a priori distinction between "structural" and "cyclical" components as well as in the econometric methodologies employed.14 The foregoing considerations have led us to choose the least prejudged empirical strategy. In line with the theoretical structure of Section 2, we have assumed that the year before our sample started (i.e., in 1961) the values for primary expenditures, fiscal revenues, public debt and interest payments were exactly at their target, and that from the following year onwards all these fiscal variables, if undisturbed, would grow along their balanced growth path, i.e. at a rate equal to the potential GPD growth rate, i.e.:

$$
\Delta g^{*}{ }_{t}=\Delta \tau^{*}{ }_{t}=\Delta b^{*}{ }_{t}=\Delta I P^{*}{ }_{t}=\Delta y^{*}{ }_{t} .
$$

\footnotetext{
14 See Perotti (2002), Galì and Perotti (2003), Melitz (2005) for recent discussions of these problems.
} 


\section{Econometric analysis}

The source for the data are yearly observations for each primitive variable in the OECD CD-Rom Database over the period 1962-200415. Elaborations on primitive variables to obtain estimation variables are those described in paragraphs 2.1 and 2.2. Time series of selected estimation variables are reproduced in Appendix, figure 1. We have used the 3SLS method with instrumental variables to correct for simultaneity. As to the time structure of the model, unconstrained estimation of system (7)-(11) would be too demanding in our case given the insufficient amount of observations relative to the number of coefficients to be estimated. Thus, we have proceeded by imposing resctrictions based on a priori theoretical or empirical information.

In the first round (Estimation I),

- we have restricted the time structure of system (7)-(11) to current and 1period lagged values of all variables; a justification for this choice may be that all variables are first differences, and it is known that such variables generally display low order or no autoregressive structures

- as regards the monetary policy equation (9), we have further restricted the time structure to contemporaneous values of explanatory variables only; first, because there are neither theoretical foundations nor existing empirical results that justify the inclusion of lagged values for the inflation and growth targeting variables; second, because though current estimates of monetary policy rules provide some evidence that lagged values of the interest rate are significant on a very short term basis ("interest rate smoothing"), yearly observations suggest that the adjustment process has fully been accomplished.

No estimated equation, except (9), has obtained statistically significant coefficients.

This result has confirmed our prior that data in first-difference of rates of deviation do not display significant autoregressive structures.

15 Primitive variables are: Gross domestic product at current market prices (ITA, GER, US), Potential output at current market prices (ITA, GER, US), GDP deflator $(1995$ = 100) (ITA, GER, US), Government non-interest expenditure at current market prices (ITA, GER), Government interest payments (ITA, GER), Total tax revenue at current market prices (ITA, GER), Government net borrowing and lending (ITA, GER), Public debt (ITA, GER), Short-term interest rate (ITA, GER), 
Hence, subsequently we have run alternative estimations under further restrictions, the main being that all lagged endogenous variables, except inflation in equation (9), were dropped from their own equation. In particular, in Estimations II and III we have further resctricted the time structure of equations for real variables (7), (10), (11) according to two alternative hypotheses both present in the relevant literature ${ }^{16}$. The first hypothesis (Estimation II) is that deviations from the growth paths of private spending, public spending and taxation affect GDP in the same year, but observed GDP growth gaps affect the fiscal variables with 1-year lag (decision-making and administrative processes, and build-up time delay implementation). The second hypothesis (Estimation III) goes the other way round (policy reaction is contemporaneous, but it is economic effects after implementation that take time to unfold) ${ }^{17}$. As is often the case, estimation results do not allow for univocal ranking of the alternative specifications. However, the most satisfactory outcome along the threefold dimension of statistical significance, theoretical consistency and empirical plausibility with pre-existing evidence has been produced by Estimation III. In the system's unrestricted reduced form (URF) for both countries no test has revealed any considerable problem: no evidence of significant first order residual autocorrelation and normality seems a good approximation to the residuals distributional shape. Therefore, we have considered the system specification and its lag structure as a congruent representation of the data. The results, with the instrumental variables employed, are presented in Table 1.

Equation for $\Delta \hat{y}_{t}$. One variable is strongly significant ( $p$-value $<5 \%$ ) with expected (negative) sign for both countries, that is the change in the real interest rate anticipated one year earlier (that should trigger a deviation of private expenditure from its growth path one year earlier). The US GDP growth gaps, that we interpret as world business cycles, turn out to be strongly significant for Germany, but very weakly significant or rejectable for Italy ( $p$-value $>10 \%)$. For both countries, the two (1-year

16 See e.g. recent econometric works on VAR models of fiscal policy (Galì and Perotti (2003))

17 This second hypothesis also hinges on the extent of so-called "automatic stabilizers" in the fiscal system: the larger their share, the faster the cyclical response of the fiscal variables. 
lagged) fiscal variables present the expected sign, but are definitely nonsignificant ${ }^{18}$.

As a matter of fact, the relationship between GDP and fiscal variables is notoriously open to debate. Not only is the evidence inconclusive, but different views are deeply rooted in theoretical unresolved issues. To say the least, international evidence allows no firmer conclusion than that the effects of fiscal variables on GDP may differ substantially across countries, in some countries being apparently weak and/or shrinking over time (see e.g. more recent works by Perotti (2002), Galì and Perotti (2003)). However, as explained above, our estimation differs from most of the reference literature in that it yields the exact elasticity of GDP growth gaps to real fiscal variables growth gaps. Hence, our results may have a statistical origin in that GDP growth gaps show low variability vis-à-vis remarkably high variability of rates of change in real fiscal variables. On the other hand, at least for Italy, the latter also embody the high variability of the inflation rate, which is not under direct control of fiscal policy. It should also be considered that GDP growth gaps may be due to a combined deviation of observed GDP growth from the potential path and a shock to the path itself. There seems to be a possible paradox here. Suppose that both observed and potential GDP depend on real fiscal variables (see e.g. Barro (1990)); then if, say, during a downturn the government spends more and/or taxes less, the result may be that the observed GDP rises while the potential GDP is also revised upwards to the effect that the gap is not closed.

Equation for $\Delta \pi_{t}$. The estimated equation supports the "accelerationist" version of the AS curve for both countries, though Germany displays negligible persistence of changes in the inflation rate, whereas Italy shows a remarkably large effect of GDP growth gaps.

Equation for $\Delta i_{t}$. No component of our "accelerationist" monetary policy equations is to be rejected statistically, with the theoretical sign and with high confidence ( $p$-values $<5 \%$ ). As to Italy, between the inflationtargeting hypothesis based on the German inflation rate and the one based on the German interest-rate parity constraint, estimates show that introduction of the latter displaces the former in significance, so that table 1 reports this specification. Our interpretation is that the Bank of Italy has

18 In the alternative estimations the two fiscal variables are always non-significant and with the wrong sign. 
substantially tracked the interest-rate parity with Germany, corrected for the risk premium proxied by the excess growth rate of public debt, while trading-off GDP growth gaps. As regards the alternative specifications for Germany (one with the reconstructed time variant inflation target and one with the imposed constant target of $2 \%$ ), the two, as was to be expected, are statistically undistinguishable from the actual change in the inflation rate, which results to be significant and with the correct positive sign.

As one may expect, our estimated monetary-policy equations show that in Italy more weight has been given to growth-targeting than to inflation-targeting whereas the opposite occured in Germany. On the other hand, the so-called "Taylor principle" materializes in neither country, that is to say the estimated coefficient of the inflation gap is, in fact, less than one. Notably, the rate of change of public debt, unlike Italy, turns out to be nonsignificant for Germany. We believe that this is an expected and informative result. In fact, as explained above, we have introduced this variable as a measure of the fiscal pressure on the real interest rate that the central bank is assumed to adopt as the anchor of its nominal interest-rate policy. It comes therefore with no surprise that in two countries with sharp differences in the speed of public-debt growth, the monetary policy rules differ in that the central bank facing slow-growing debt (Germany) has given no weight to this variable, whereas the one facing fast-growing debt (Italy) has given substantial weight to it.

Equations for $\Delta g_{t}$ and $\Delta \tau_{t}$. First of all, both countries display sizeable anti-cyclical contemporaneus components of the rate of change of real fiscal variables. In fact, the parameters of GDP growth gaps are strongly significant and with the theoretical sign ( $p$-values $<5 \%$ ). Traditional wisdom concerning the "long and variable lags" of fiscal policy does not seem confirmed, or else, the importance and extent of in-built stabilizers is vindicated (see also Melitz (2005)). The information we gain about the magnitude of elasticites to contemporaneous growth gaps is that

- expenditure elasticity is about -1.1 in both countries

- taxation elasticity is about 0.5 in Italy and 1.8 in Germany

At first sight, both elasticities in the two countries are much larger than in other empirical studies, where they result around 0.3 in absolute value, and where 0.5 is regarded as the typical elasticity of the total budget (see e.g. Giorno et. al. (1995), Artis and Buti (2000), van den Noord (2000), Brunila et al. (2002)). Italy is also at variance with received wisdom which 
wants taxation as the more elastic stabilizer. Yet, as already discussed previously, our results are not directly comparable with strandard practice in the field which typically a) estimates fiscal rules in isolation, and b) measures the elasticity of fiscal-GDP ratios to output gaps, both in levels. A measurement (partially) comparable to ours has been proposed by Melitz (2005, Table 1a) who, in a panel of euro-countries, has in fact found slightly lager values of the elasticities of first differences of both public expenditure and taxation to first differences in output gaps. It should also be considered that the difference between our estimated values and the others may simply be due to the algebra of respecification (empirically, estimates may be roughly equivalent) ${ }^{19}$. Anyway, our aim here is not so much to dispute the magnitude of the cycle elasticites of fiscal variables as to focus on the implications of our proposed change of approach with regard to the assessment of the government budget over the cycle, one implication being that knowing such elasticities, if ever possible, per se conveys little information. These implications will be clarified with the help of the simulations.

Neither Italy nor Germany pass the budget-smoothing hypothesis, that is sensitivity of primary fiscal variables to the evolution of interest payments. The respective parameters are negligible in size and nonsignificant (in all alternative estimations too). If taken at face value, only Italy displays the correct sign. This result may disappoint the presumption that at least Germany had a well-behaved fiscal rule20. Another interpretation is, however, possible, which is consistent with the difference

${ }^{19}$ Consider any fiscal variable in isolation $f_{t}$, in relation to a cyclical measure of GDP only. Our "growth-gaps" specification is

$$
\Delta \hat{f}_{t}=\alpha+\beta \Delta \hat{y}_{t}+u_{t}
$$

Upon expanding this expression according our definition of growth gap and rearranging, it is possible to obtain a respecification in the following form:

$$
\left(f_{t}-y_{t}\right)=\alpha+\left(f_{t-1}-y_{t-1}\right)+(1-\beta)\left(y_{t}-y^{*}{ }_{t}\right)+(1-\beta)\left(y_{t-1}-y_{t-1}^{*}\right)+u_{t}
$$

This is the standard specification of an estimation equation for the fiscal variable / GDP ratio $\left(f_{t}-y_{t}\right)$ in level, regressed on its own lagged value and on the current and lagged value of the output gap in level (see e.g. Melitz (2002) and Favero (2002)). Clearly, the cyclical coefficents estimated in the standard specification are complements to those estimated by way of the "growth-gaps" specification; if the former are smaller than 0.5 , the latter will result larger than 0.5 .

20 On the other hand, Favero (2002) has found that both Germany and Italy performed budget-smoothing to some extent. 
in the two countries' monetary rules that have beeen detected above. Namely that a virtuous fiscal-monetary circle was in place in the slowgrowing-debt country (Germany) and a vicious one in the fast-growing-debt country (Italy). In the former country, the mutual sensitivity between fiscal and monetary policy is negligible as slow-growing debt, low and stable interest rate and sustainable interest payments are mutually consistent. The opposite occurs in the latter country, where the fast-growing debt forces mutual sensitivity between fiscal and monetary policy.

\section{Simulations}

By means of the estimated system, it has been possibile to simulate the responses of the endogenous variables to exogenous shocks ${ }^{21}$. Here we only report as an example the results of a $-1 \%$ temporary shock to the GDP growth below potential at time 0 (1963), with no other shock thereon. The simulation yields, for each endogenous variable, the percent rate of deviation from the correspondent baseline value (which, for analogy with the theoretical model, we still denote by $\left.\Delta\left({ }^{\wedge}\right)\right)^{22}$. Recall that in our model the baseline value is a growth rate for all real variables and the price level, and a constant for the nominal interest rate.

In order to gather information on the government budget, we have also used the simulated dynamics of the endogenous variables to compute relevant compound budget variables such as
- real primary balance:
$\Delta \hat{P} B_{t}=\Delta \hat{\tau}-\Delta \hat{g}$
- real interest payments:
$\Delta \hat{I} P_{t}=\Delta i_{t}-\Delta \hat{\pi}_{t}$
- total budget:
$\Delta \hat{B}_{t}=\Delta \hat{P} B_{t}-\Delta \hat{I} P_{t}$

Thus, in the simulation, the primary balance deviates from its baseline value by the difference between the deviations of the tax revenue

\footnotetext{
21 The simulation software was WinSolve.

22 It should be borne in mind that the simulator creates the baseline value of each endogenous variable for each point in time by means of an initial simulation of the estimated system whereby the system is fed with the "true" times series of the exogenous variables used in the econometric estimation. These same time series are also used in the simulation. Hence, the simulation results should be understood as deviations of the endogenous variables from their "historical" estimated values in the absence of shocks. This procedure also implies that simulation results are "history sensitive" in that they depend on the shock date chosen and on the true historical values of the exogenous variables.
} 
and of the the primary expenditure. The deviation rate of real interest payments is approximated by the change of the real interest rate on outstanding debt. As to total budget, it deviates form its baseline value by the difference between the deviations of interest payments and of the primary balance.

The graphs in Appendix (figures 2 and 3) show the post-shock dynamics of the five primitive endogenous variables $\left(\Delta \hat{y}_{t}, \Delta \hat{\pi}_{t}, \Delta \hat{i}_{t}, \Delta \hat{g}_{t}\right.$, $\left.\Delta \hat{\tau}_{t}\right)$ and of the two generated variables $\left(\Delta \hat{P} B_{t}, \Delta \hat{B}_{t}\right)$ for the two countries. The following comments are in order.

Stability and transitory dynamics. All variables are dynamically stable with low persistence in both countries. In fact, deviations in all variables shrink to zero in a relative small number of rounds. In other words, each variable returns to its baseline value. Transitory dynamics is almost monotonic for all variables in both countries, except inflation in Italy. It is also consistent with standard macroeconomics. As regards Italy, on impact we see a typical pattern of demand shock: the negative growth gap triggers a deceleration in the inflation rate and anti-cyclical policy adjustments. The nominal interest rate is reduced though less than the deceleration of inflation: the real interest rate deviates above the neutral rate most of the time. Fiscal stabilization consists of a sequence of impulses accelerating primary expenditure and decelerating tax revenue with respect to baseline growth rates. Consequently, the economy is set on a path of negative growth gaps of decreasing magnitude up to zero. Germany instead shows a typical pattern of supply shock: on impact of the negative growth gap the simulation yields an acceleration of inflation. Now the policy variables react in opposite directions. The nominal interest rate immediately rises, though not as much as the acceleration of inflation; yet subsequent adjustments bring the real interest rate above the neutral rate. Fiscal variables react to the negative GDP growth gap as expected until the gap is progressively reduced to zero.

Elasticities and stabilization capacity: measurement puzzles. How should we measure stabilization capacity, and the ensuing budget requirements correctly? Are estimated elasticities of fiscal variables to a cyclical measure of GDP really informative? If fiscal variables do respond "automatically" to growth shocks, these "shocks" - as they are usually intended in models - are unobservable, while estimates are based on observed data which probably already embody at least some of the 
stabilization effects of fiscal variables on GDP and vice versa. Our simulation exercise allows us to disentagle this matter. First, we have a well defined shock, and secondly we can track the reponse of fiscal variables precisely up to the new steady state. We can thus distinguish (at least) two measures of elasticities with respect to the shock, a) on impact of the shock, and b) in the new steady state, that is the cumulated rates of deviation of fiscal variables from target necessary to nullify the initial GDP growth gap (the "integrals" of the graphs in figures 2 and 3). The respective values are reported in table 2 .

As can be seen, steady-state elasticities are smaller than impact ones, with one important exception. Let us look at the primary versus total budget. In Italy as well as in Germany, on impact both variables deteriorate relative to their baseline value by roughly the same amount (about 1.7\% in Italy and $1.0 \%$ in Germany). However, the paths of the primary and total budgets differ markedly in Italy with respect to Germany (see figures 2 and 3 , panel (f)). In the latter country the two measures of fiscal stance roughly follow the same monotonic path. In Italy, by contrast, the total budget worsens at higher (absolute) rates and for a longer time than the primary budget. Hence, the steady-state elasticity of the total budget is amazingly higher in Italy than in Germany, though the underlying fiscal rules are quite similar in the two countries. The difference is due to real interest payments. As we know, in Italy, though the nominal interest rate is reduced, the inflation rate decelerates even more imposing a sequence of inflation-tax cuts. Thus, real interest payments rise most of the time, whereas the opposite occurs in Germany.

This exercise provides an instance of the idea that the total budget is not under full control of the government over the cycle even when the government does "let the automatic stabilizers work" and does not engage in discretionary activism. Even if an almighty econometrician could tell us the exact elasticities of primary fiscal variables to growth shocks, still we would be unable to infer the evolution of the government budget unless we also knew all the details of the underlying macroeconomic process. A major "detail" is that the actual cyclical evolution of total budget is closely dependent on the concomitant monetary-fiscal interactions.

Monetary-fiscal interactions. Since in Italy more weight is given to growth-targeting than to inflation-targeting whereas the opposite occurs in Germany, this may explain the handbook reactions of monetary policy both 
in the deflationary case of Italy and in the stagflationary case of Germany. On the other hand, the nominal interest rate does not over-react to deviations of inflation from target causing, at first sight, unintended movements in the real interest rate: it rises in Italy and falls in Germany (at least initially). One reason may be that in both countries the estimated coefficient of the inflation gap is, in fact, less than one. Another reason of interest is that our monetary-policy equations also respond to public debt dynamics as a determinant of the neutral real interest rate. As remarked above, the coefficient of this variable is significant and positive for Italy whereas it is not for Germany. Since this variable in the sample period of the simulation is rapidly increasing in Italy, the ensuing "fiscal spillover" may reduce the responsiveness of monetary policy and sustain the rise in the real interest rate. Now let us look at the other side of the monetaryfiscal interactions. The channel of interaction going from the monetary to the fiscal side on which we have focused in our model is interest payments. These enter the fiscal equations under the hypothesis of "budget smoothing" on the part of governments. Estimation results reject this hypothesis for both countries. Nonetheless, interest payments also exert direct influence on the evolution of the total budget as seen above.

One may be tempted to conclude from our exercise that in a slowgrowing-debt country not only are fiscal and monetary policy complements 23 but can also be (virtually) independent. By contrast, in a fast-growing-debt country the two policies may still be complements but not independent. As a consequence, in the first type of country both policies can be more aggressive with less overall impact on the total budget, whereas in the second type of country one policy checks the other and nonetheless they leave an overall negative effect on the total budget.

Rates of deviations, levels and the SGP rules. Let us finally examine the debated question of the cyclical evolution of the deficit/GDP ratio. To this end, we have to go back from rates of deviation to levels, which also ease comparison between our results and existing ones. The interpretation of the foregoing results within our theoretical model is that the growth rates of output, tax revenue, primary expenditure and prices return to their

23 It should be stressed that complementarity emerges in our simulation of a GDP shock. Preliminary inspections of different shocks, such as inflationary or fiscal shocks, indicate that the two policies are used as substitutes. A similar result can be found in Muscatelli et al. (2004). 
respective initial values. This, however, does not imply that the levels of those variables will thereon be equal to those that would have obtained along the growth path of the economy in the absence of the shock. To verify this property, the simulation data in rates of deviations from baseline values can easily be converted into data in levels (index numbers) 24 . This exercise shows that, for instance, a temporary negative gap in the growth rate of output determines a permanent output gap in levels. Likewise, a temporary positive growth gap in public expenditure will end up with a permanent positive gap in level, etc. In this respect, an important information is given by the cumulative deviations of the variables discussed above, which determine the respective gaps in levels in the new steady state. The latter are reported in table 3 both for absolute fiscal variables and for their GDP ratios

Let us first consider final output gaps, which are $-1.04 \%$ for Italy and $-0.57 \%$ for Germany. This means that in Italy the initial growth shock leaves behind a permanent output gap of the same magnitude, whereas in Germany it is almost halved. In both countries the bulk of stabilization is borne by primary expenditure (particularly in Italy) rather than by taxation as presumed by most studies on automatic stabilizers (on this point see also Melitz (2005)). Remarkably, however, the stronger stabilization capacity of Germany is obtained with less fiscal effort as measured by the cumulative deterioration of the primary balance, which reaches $-1.57 \%$ of baseline value in Italy but stops at $-0.94 \%$ in Germany. Notice that figures are somewhat different if measured in ratios to GDP: in particular, the expenditure/GDP and taxation/GDP ratios are larger than the gaps in absolute terms (overestimating the increase in expenditure and underestimating the reduction in taxation - which even appears to have been increased). The well-known reason is that GDP ratios embody the lower level of the denominator 25 .

24 Let $X_{0}=100$ be the initial absolute value of any variable. Then for any $t=1, \ldots$, the new level along the steady-state growth path of the economy is given by $X^{*}{ }_{t}=X^{*}{ }_{t-1}\left(1+q^{*}\right)$, whereas the new level after the shock is given by $X_{t}=X_{t-1}(1+$ $\left.q^{*}{ }_{t}+\Delta \hat{x}_{t}\right)$. We have taken $q^{*}{ }_{t}$ to be the potential growth rate of GDP in the data set for each country, and, according to the theoretical model, we have used it also for fiscal variables.

25 The figures in table 3 further exemplify the pitfalls of estimation of ex-post elasticities mentioned previously. These figures in fact closely resemble the typical statistical information available, that is realized output gaps on the one hand, and 
In any case, these figures deliver an important message that concerns the new exemption clauses introduced by the SGP reform. As reported in the Introduction, these clauses correctly recongize that not only negative growth rates, but also "prolonged" negative growth gaps (while the absolute growth rate may remain positive) may account for "exceptional" fiscal deficits. They also give right relevance to the related concept of "cumulated loss of output". These are welcome amendments, which however will need careful re-examination of assessment criteria of fiscal stances of member countries.

First of all, unlike the sparse occurences of the old definition of "exceptional recessions" found by Buti and Sapir (1998) from 1961 to 1997, one should expect statistics - if not interested governments - to report negative growth gaps roughly half of the times owing to the sheer statistical artifact that these are stationary variables around the trend (see figure 1). And we have seen that econometric analysis does support the hypothesis that fiscal variables are highly sensitive to this measure of the business cycle. Further, cycles are typically characterized by strings of negative and positive growth gaps. Consequently, strings of negative years impinging upon fiscal balances are frequent events rather than exceptional ones. Our simulated steady-state elasticities suggest that in a country like Italy, even starting from balance, the 3\% deficit/GDP ratio might be reached after 2 years of negative growth gaps in the order of $1 \%$, not an infrequent occurence in the sample. These findings shed doubts on early assessments on the substantial safety margin guaranteed by the $3 \%$ deficit ceiling (e.g. Buti and Sapir (1998), Artis and Buti (2000)).

Secondly, we have seen that "cumulated losses of output" indeed have far reaching consequences. Temporary growth gaps leave long-lasting traces in public finances, even in well-managed (simulated) public finances. Looking at the statistics of our simulated economies, the SGP guardians might be tempted to conclude that, as the GDP is driven back to its potential growth rate, there is no longer justification for a deficit. However, the extant primary deficit - not to mention the total deficit - though created

changes in absolute fiscal variables or in their GDP ratios on the other. Yet table 3 makes it apparent that, whereas the data have been generated by the same growth shock in the two countries, ex-post elasticites in Germany would be grossly overstimated for the mere fact that stabilization has been more effective. 
by "legitimate" cyclical factors, becomes, in a sense, structural. It is bound to last until a new positive impulse to growth overcomes the previous cumulative output loss. True, as we argued above, at each point in time there is about a 50\% chance that this happens. But what is, then, an "excessive deficit"? And how is it ascertained the return to normality? At the moment it is unclear whether and how the SGP institutions are ready to address these crucial questions.

\section{Conclusions}

Was it by chance that the breakdown of the SGP excessive deficits procedure occured after three years of stagnation, if not recession, in the euro area and the quest for reform was led by the two early guardians of the SGP orthodoxy?

In this paper we have sought to reframe the matter of the role of fiscal policy in the macroeconomic process in vew of the implementation of fiscal rules within a consistent macroeconomic model whereby the cyclical dynamics of GDP, inflation, monetary and fiscal variables are jointly determined. As an empirical innovation, we have specified the model in terms of growth gaps, rather than level gaps, consistently with the common perception and measurement of business cycles as well as with the new exemption clauses introduced by the reformed SGP. In the paper we have reported some results of estimation of the model for Italy and Germany, and of subsequent simulations of a negative growth gap shock. These results need further refinements and controls. Yet the foregoing findings prompt a few considerations concerning the implementation of the SGP (revised) rules.

To beign with, a few measurement problems have emerged and have been addressed. As also indicated by Melitz (2005), we have seen that broad measures of public expenditure and taxation do respond to the business cycle, and hence we cannot but agree with this author that the larger these items the better. The implication is that not much of observed changes in fiscal variables can undisputably be subtracted from anti-cyclical stabilization. In other words, the body of evidence in order to open excessive deficits procedures may be very limited if excessive should mean beyond legitimate anti-cyclical deficits. There is also a normative side of this statistical finding. The Commission's popular view that the EMU 
governments ought simply "let the automatic stabilizers work", the more is viable the larger the extent of anti-cyclical fiscal variables. This cannot but legitimate the great prudence, if not reluctance, of most governments towards dismantling public safety nets as is often recommended by the Commission itself (see also Farina and Tamborini (2004)).

We have also shown that attempts at measuring the cyclical components of fiscal variables by means of estimated elasticities to some measure of the business cycle are undermined by several pitfalls. With the help of simulations, we have obtained what we think the theoretically correct measure of these elasticities, the steady-state rates of deviations in absolute fiscal measures in response to intial GDP growth gap (last column table 2). True, this measure can hardly be obtained in practice; yet researchers should be aware that measures obtained on observable data, which probably contain at least part of the stabilization effect of fiscal variables on GDP, tend to overestimate the magnitude of elasticities (especially if measured as GDP ratios), the more so the more effective are fiscal variables.

It is once again confirmed that the long-standing scepticisms and criticisms about the choice of the total deficit/GDP ratio as the pillar of the SGP rules are not groundless. Beside the aforementioned measurement problems, our simluations have highlighted how the sensitivity of such an indicator to the business cycle and to monetary policy may seriously mislead the assessment of the actual fiscal stance of a government. The use of this indicator seems at variance with the prescription in the recent developments of the theory of policy rules according to which rules should make refernce to, and policy-makers should be assessed on, instruments that they can control, not outcomes they do not control (Woodford (2003, ch. 1)). On the other hand, the imposition of a fixed and equal ceiling for all countries is likely to interfere with sound stabilization policy.

The shift of focus towards growth gaps also in the new exemption clauses of the SGP implies far reaching modifications in the assessment of fiscal stances of member countries, and in the ensuing policy prescriptions. The relative frequency of negative strings of growth gaps, combined with the responsiveness of large fiscal aggregates to these gaps, shed doubts on the view that the $3 \%$ deficit ceiling allows sufficient saftey margin for cyclical manouvre. What is more important, we have shown that these episodes, even though triggered by temporary shocks, determine permanent output 
losses to which there correspond permanent primary deficits. These will not be reabsorbed by mere return to "normal" growth. Hence it is not clear how the Commission will assess these situations.

Corrections and exemptions progressively introduced in the SGP have pointed to the right directions, but have not been, and will not be, effective means to solve these problems. Overall, our judgement is that the revised SGP neither has fixed its fundamental flaw - the misuse of a cyclical variable like the deficit/GDP ratio to gauge "excessive deficits" that should instead be assassed against the long-run sustainability of public debt growth - nor has introduced effective safeguards for the stabilization role of fiscal policy. Making the application of a "stupid" rule more "flexible" will not transform it in an intelligent rule but in an empty rule.

\section{References}

A.E.A. (1997), "Is There a Core of Practical Macroeconomics That We Should All Believe?", Panel at the American Economic Association, New Orleans, LA, January 4-6, 1997, Papers and Proceedings of the American Economic Association, American Economic Review, 87, 230246.

Allsopp C., Vines D. (2000), "The assessment: macroeconomic policy", Oxford Review of Economic Policy, 16:1-32.

Angeloni I. 1994, "Strumenti e obiettivi operativi della Banca d'Italia: verso un modello europeo", Note Economiche, 14, 128-161.

Artis M., Buti F. (2000), "Close to Balance or in Surplus. A Policy Maker's Guide to the Implementation of the Stability and Growth Pact", Journal of Common Market Studies, 38: 563-592.

Barro R.J. (1990), "Government spending in a simple model of endogenous growth", Journal of Political Economy, 98:103-125.

Bean C. (1998), "The new monetary arrangements: a view for the literature", Economic Journal, 108:1795-1809.

Begg D., et al. (1999), Monitoring the European Central Bank, London, CEPR.

Benigno P., Woodford M. (2000), "Optimal monetary and fiscal policy: a linear quadratic approach", mimeo.

Brunila, Anne, Marco Buti and Jan in't Veld (2002), "Fiscal Policy in Europe: How Effective Are Automatic Stabilizers?", European Economy, Economic Papers, 177.

Buti M., Eijffinger S., Franco D. (2003), "Revisiting the Stability and Growth Pact: Grand Design or Internal Adjustment?", European Economy, Economic Papers,180. 
Buti M., Franco D., Ongena H. (1998), "Fiscal discipline and flexibility in EMU: the implementation of the Stability and Growth Pact", Oxford Review of Economic Policy, 14:81-97.

Buti M., Sapir A. (1998), Economic Policy in EMU. Oxford, Clarendon Press.

Buti M., Franco D. (2005), "The Stability Pact's pains: A forward-looking assesment of the reform debate", CEPR Discussion Paper Series, 5216.

Clarida R., Galì J., Gertler M. (1999), "The science of monetary policy: a new Keynesian perspective", Journal of Economic Literature, 37:16611707.

Dixit A., Lambertini L. (2001), "Monetary-Fiscal Interaction and Commitment versus Discretion in a Monetary Union", Papers and Proceedings of the European Economic Association, European Economic Review, 45, pp.977-987

Dornbush R., Favero C.A., Giavazzi F., (1998) "Immediate Challenges for the European Central Bank", Economic Policy, 26, pp.15-64

Farina F., Tamborini R. (2002), "Le politiche macroeconomiche di stabilizzazione in Europa nel nuovo regime di unione monetaria", in Farina F., Tamborini R. (eds), Da Nazioni a Regioni. Mutamenti Strutturali e Istituzionali Dopo l'Ingresso nella Unione Monetaria Europea. Bologna, Il Mulino.

Farina F., Tamborini R. (2004), "'Set a sufficiently ambitious budget target and let the automatic stabilizers work'. Can It really work in the European Monetary Union?", Open Economies Review, 15:143-168.

Favero C. (2002), "How Do European Monetary and Fiscal Authorities Behave?", CEPR Discussion Paper Series, 214

Galì J., Perotti R. (2003), "Fiscal policy and monetary integration in Europe", Economic Policy, 37:533-572.

Geberding C., Worms A., Sietz F. (2004), "How the Bundesbank really conducted monetary policy: An anlysis based on real-time data", Discussion Paper No. 25/2004, Deutsche Bundesbank

Giavazzi F., Pagano M. (1988), "The advantage of tying one's hands: EMS discipline and central bank credibility", European Economic Review, 32:371-390.

King R.G. (2000), "The new IS-LM model: language, logic, and limits", Federal Reserve Bank of Richmond Economic Quarterly, 86:45-103.

Krugman P. (2000), "How complicated does the model has to be?", Oxford Review of Economic Policy, 16:33-42.

Leith C., Wren-Lweis S. (2000), Interactions between monetary and fiscal policy rules, Economic Journal, 110:93-108.

McCallum B.T., Nelson E. (1999), "An optimizing IS-LM specification for monetary policy and business cycle analysis", Journal of Money, Credit and Banking, 31:296-316.

Mélitz J. (2002), "Some Cross-Country Evidence about Fiscal Policy Behaviour and Consequences for EMU", in Buti M., Von Hagen J., 
Martinez-Mongay C., The Behaviour of Fiscal Authorities, Basingstoke: Palgrave.

Melitz J. (2005), "Non-discretionary and automatic fiscal policy in the EU and the OECD", mimeo.

Muscatelli V.A., Tirelli P., Trecroci C. (2004), "Fiscal and monetary policy interactions in a new Keynesian model with liquidity constraints", Journal of Macroeconomics, 26:257-280.

Perotti R. (2002), "Estimating the effects of fiscal policy in OECD countries, ECB", ECB, Working Paper Series, no. 168.

Tamborini R. (2004) "The 'Brussels consensus' on macroeconomic stabilization policies in the EMU. A critical assessment", in Torres F., Verdun A., Zilioli C., Zimmermann H. (eds), Governing EMU: Political, Economic, Historical and Legal Aspects. Florence, European University Press.

Taylor J.B. (1993), "Discretion versus policy rules in practice", CarnegieRochester Conference Series on Public Policy, 39:195-214.

Taylor J.B. (ed.) (1999), Monetary Policy Rules. Chicago, University of Chicago Press.

Taylor J.B. (2000a), "Reassessing discretionary fiscal policy", Journal of Economic Perspectives, 14:21-36.

Taylor J.B. (2000b), "The policy rule mix: a macroeconomic policy evaluation", in Calvo G, Obstfeld M., Dornbusch R. (eds), Robert Mundell Festschrift. Cambridge, MIT Press.

Visco, I. (1995), "Inflation, inflation targeting and monetary policy: notes for discussion on the Italian experience", in Leiderman, L., Svensson L.E.O. (eds), Inflation Targets. London, CEPR.

Woodford M. (2003), Interest and Prices”, Princeton, Princeton University press. 
Table 1. Estimation results by 3SLS. Standard errors in brackets. $(* *),(*)$ indicate significance at $5 \%, 10 \%$ level, respectively.

\begin{tabular}{|c|c|c|c|c|c|}
\hline \multicolumn{3}{|c|}{ Italy } & \multicolumn{3}{|c|}{ Germany } \\
\hline \multirow{6}{*}{$\Delta \hat{y}_{t}$} & Constant & $\begin{array}{c}0.002 \\
(0.002)\end{array}$ & \multirow{6}{*}{$\Delta \hat{y}_{t}$} & Constant & $\begin{array}{l}-0.004 \\
(0.002)\end{array}$ \\
\hline & $\Delta \hat{r}_{t-1}$ & $\begin{array}{c}-0.357^{* *} \\
(0.048)\end{array}$ & & $\Delta \hat{r}_{t-1}$ & $\begin{array}{c}-0.205^{* *} \\
(0.089)\end{array}$ \\
\hline & $\Delta \hat{g}_{t-1}$ & $\begin{array}{c}0.006 \\
(0.048)\end{array}$ & & $\Delta \hat{g}_{t-1}$ & $\begin{array}{c}0.108 \\
(0.126)\end{array}$ \\
\hline & $\Delta \hat{\tau}_{t-1}$ & $\begin{array}{l}-0.153 \\
(0.136)\end{array}$ & & $\Delta \hat{\tau}_{t-1}$ & $\begin{array}{l}-0.024 \\
(0.062)\end{array}$ \\
\hline & $\Delta \hat{y}_{t}^{U S A}$ & $\begin{array}{c}0.115 \\
(0.078)\end{array}$ & & $\Delta \hat{y}_{t}^{U S A}$ & $\begin{array}{c}0.261^{* *} \\
(0.091)\end{array}$ \\
\hline & & & & Dummy91 & $\begin{array}{c}0.081^{* *} \\
(0.013)\end{array}$ \\
\hline \multirow{4}{*}{$\Delta \hat{\pi}_{t}$} & Constant & $\begin{array}{l}-0.000 \\
(0.003)\end{array}$ & \multirow{4}{*}{$\Delta \hat{\pi}_{t}$} & Constant & $\begin{array}{c}0.000 \\
(0.002)\end{array}$ \\
\hline & $\Delta \hat{\pi}_{t-1}$ & $\begin{array}{c}0.807^{* *} \\
(0.224)\end{array}$ & & $\Delta \hat{\pi}_{t-1}$ & $\begin{array}{c}0.245 \\
(0.161) \\
\end{array}$ \\
\hline & \multirow[t]{2}{*}{$\Delta \hat{y}_{t}$} & $\begin{array}{c}1.405^{* *} \\
(0.259)\end{array}$ & & $\Delta \hat{y}_{t}$ & $\begin{array}{l}0.377 * \\
(0.166)\end{array}$ \\
\hline & & & & Dummy91 & $\begin{array}{c}-0.020 \\
(0.017) \\
\end{array}$ \\
\hline \multirow{6}{*}{$\Delta i_{t}$} & Constant & $\begin{array}{l}-0.000 \\
(0.002)\end{array}$ & \multirow{6}{*}{$\Delta i_{t}$} & Constant & $\begin{array}{c}0.001 \\
(0.003)\end{array}$ \\
\hline & $\Delta i_{t}^{G E R}$ & $\begin{array}{c}0.599 \text { ** } \\
(0.209)\end{array}$ & & $\Delta \pi_{t}$ & $\begin{array}{c}0.619 \text { ** } \\
(0.245)\end{array}$ \\
\hline & $\Delta \hat{\pi}_{t}$ & $\begin{array}{c}0.461^{* *} \\
(0.122)\end{array}$ & & $\Delta \hat{y}_{t}$ & $\begin{array}{c}0.149^{* *} \\
(.418)\end{array}$ \\
\hline & $\Delta \hat{y}_{t}$ & $\begin{array}{c}0.682 \text { ** } \\
(0.284)\end{array}$ & & $\Delta \hat{b}_{t}$ & $\begin{array}{l}-0.040 \\
(0.069)\end{array}$ \\
\hline & $\Delta \hat{b}_{t}$ & $\begin{array}{c}0.223^{* * *} \\
(0.123)\end{array}$ & & Dummy91 & $\begin{array}{l}-0.007 \\
(0.036)\end{array}$ \\
\hline & Dummy82 & $\begin{array}{c}0.040^{* *} \\
(0.017)\end{array}$ & & & \\
\hline
\end{tabular}




\begin{tabular}{|c|c|c|c|c|c|}
\hline \multirow{4}{*}{$\Delta \hat{g}_{t}$} & Constant & $\begin{array}{c}0.010 \\
(0.004)\end{array}$ & \multirow{4}{*}{$\Delta \hat{g}_{t}$} & Constant & $\begin{array}{c}0.006 \\
(0.004)\end{array}$ \\
\hline & $\Delta \hat{y}_{t}$ & $\begin{array}{c}-1.018^{* *} \\
(0.261)\end{array}$ & & $\Delta \hat{y}_{t}$ & $\begin{array}{c}-1.185^{* *} \\
(0.348)\end{array}$ \\
\hline & $\Delta \hat{I P} P_{t}$ & $\begin{array}{c}0.008 \\
(0032)\end{array}$ & & $\Delta \hat{I P} P_{t}$ & $\begin{array}{c}-0.009 \\
(0.059)\end{array}$ \\
\hline & Dummy95 & $\begin{array}{c}-0.033 \\
(0.022) \\
\end{array}$ & & Dummy91 & $\begin{array}{c}0.170 \\
(0.040) \\
\end{array}$ \\
\hline \multirow{4}{*}{$\Delta \hat{\tau}_{t}$} & Constant & $\begin{array}{c}0.012 \\
(0.004)\end{array}$ & \multirow{4}{*}{$\Delta \hat{\tau}_{t}$} & Constant & $\begin{array}{c}0.003 \\
(0.004)\end{array}$ \\
\hline & $\Delta \hat{y}_{t}$ & $\begin{array}{l}0.520^{*} \\
(0.292)\end{array}$ & & $\Delta \hat{y}_{t}$ & $\begin{array}{l}1.854^{* *} \\
(0.297)\end{array}$ \\
\hline & $\Delta \hat{I} P_{t}$ & $\begin{array}{c}0.016 \\
(0.038)\end{array}$ & & $\Delta \hat{I P} P_{t}$ & $\begin{array}{c}0.091 \\
(0.051)\end{array}$ \\
\hline & Dummy95 & $\begin{array}{c}-0.007 \\
(0.026)\end{array}$ & & Dummy91 & $\begin{array}{l}-0.025 \\
(0.034)\end{array}$ \\
\hline \multicolumn{3}{|c|}{$\begin{array}{l}\text { Instrumental variables: } \Delta \hat{r}_{t-1}, \Delta \hat{y}_{t}^{U S A} \\
\Delta \hat{b}_{t}, \Delta \hat{I I} P_{t}, \text { Dummy95 }\end{array}$} & \multicolumn{3}{|c|}{$\begin{array}{l}\text { Instrumental variables: } \Delta \hat{r}_{t-1}, \\
\Delta \hat{y}_{t}^{U S A}, \Delta \hat{b}_{t}, \Delta \hat{I P}_{t}, \text { Dummy91 }\end{array}$} \\
\hline
\end{tabular}

Table 2. Measures of elasticities to $-1 \%$ GDP growth gap

\begin{tabular}{|l|r|r|}
\hline & \multicolumn{2}{|c|}{$\begin{array}{c}\text { Simulated elasticities } \\
\text { impact }\end{array}$} \\
\hline primary expenditure & -1.48 & -1.45 \\
total tax revenue & 0.23 & 0.20 \\
primary balance & 1.71 & 1.65 \\
total balance & 1.74 & 6.22 \\
\hline & \multicolumn{2}{|c|}{ Germany } \\
\hline primary expenditure & -0.66 & -0.59 \\
total tax revenue & 0.43 & 0.39 \\
primary balance & 1.09 & 0.98 \\
total balance & 0.95 & 1.06 \\
\hline
\end{tabular}


Table 3. Steady-state gaps in levels after the shock (\%)

\begin{tabular}{|c|c|c|}
\hline & Italy & Germany \\
\hline output & -1.04 & -0.57 \\
primary expenditure & +1.38 & +0.57 \\
ratio to GDP & +2.45 & +1.14 \\
total tax revenue & -0.19 & -0.37 \\
ratio to GDP & +0.86 & +0.20 \\
primary balance & -1.57 & -0.94 \\
ratio to GDP & -1.59 & -0.94 \\
\hline
\end{tabular}


Figure 1. Selected estimation variables, growth gaps, 1962-2004

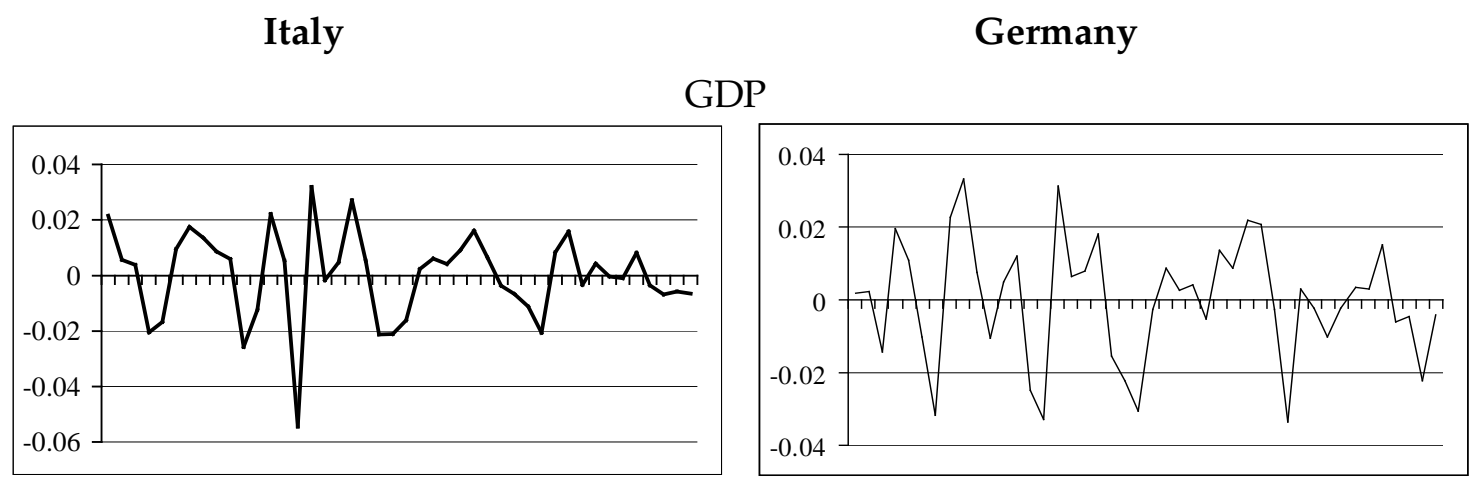

Primary expenditure

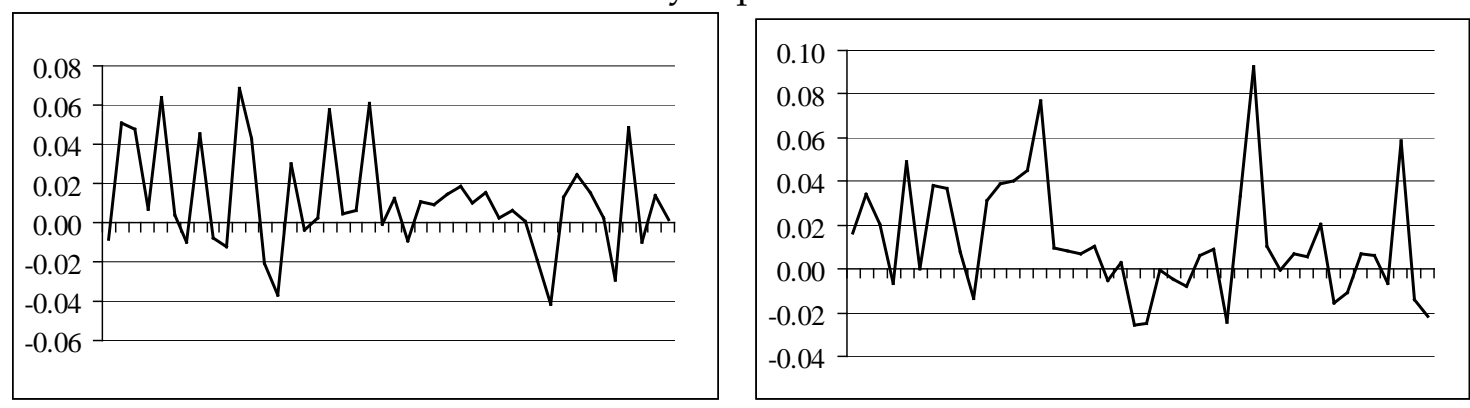

Total tax revenue
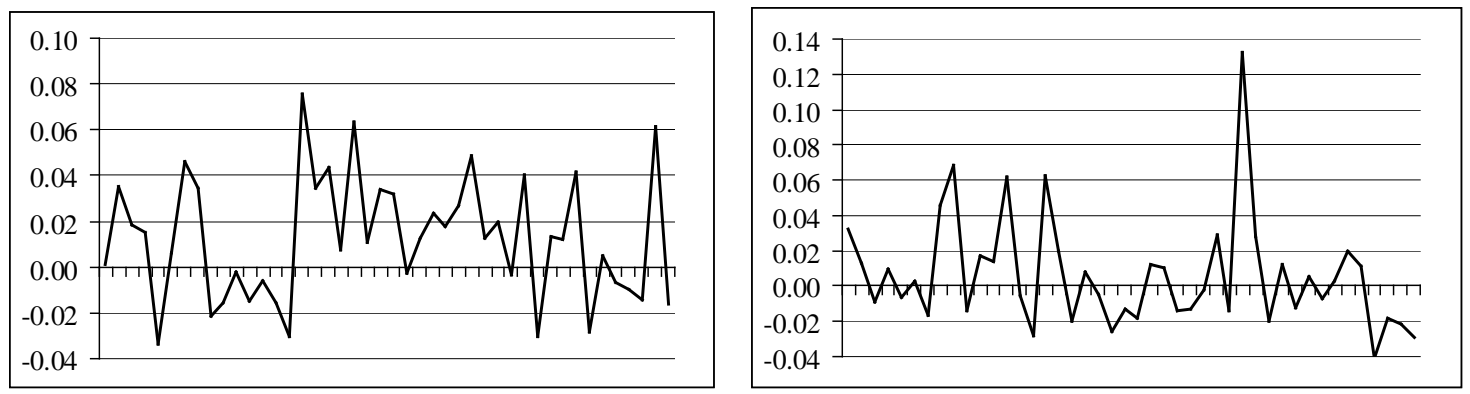
Figure 2. Italy. Responses (percent deviations from baseline values) to a temporary negative $1 \%$ multiplicative shock to the GDP growth gap.

(a) GDP growth gap

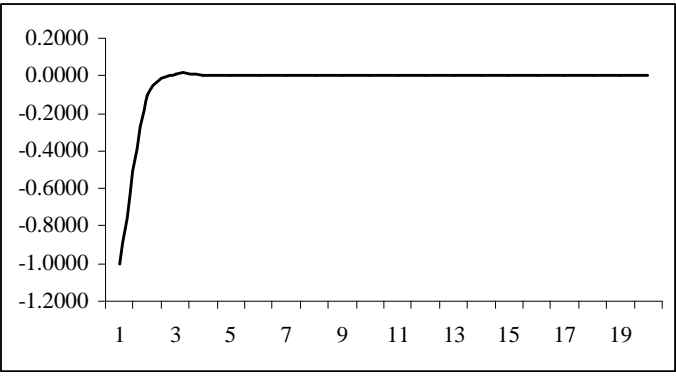

(c) Nominal (dotted) and current real interest rate (solid)

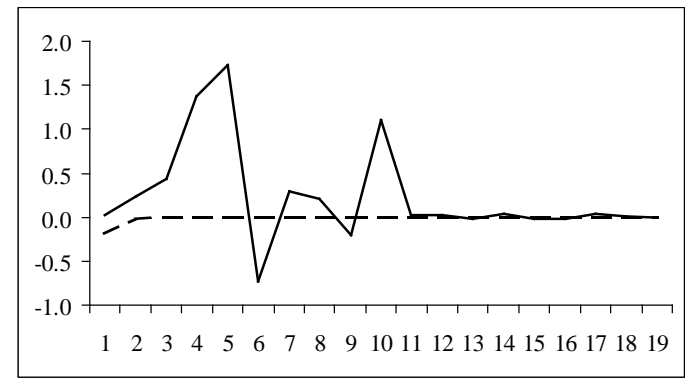

(e) Tax revenue

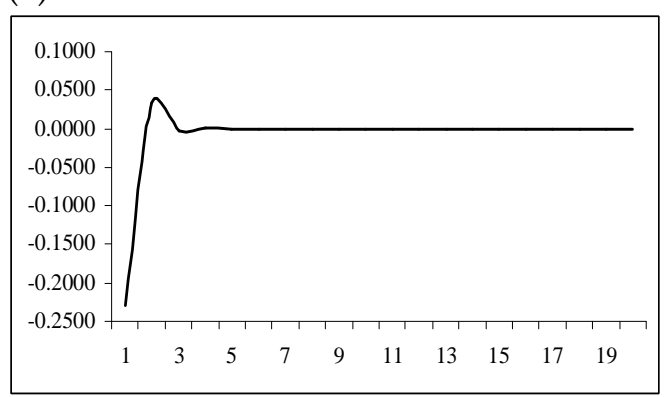

(b) Inflation

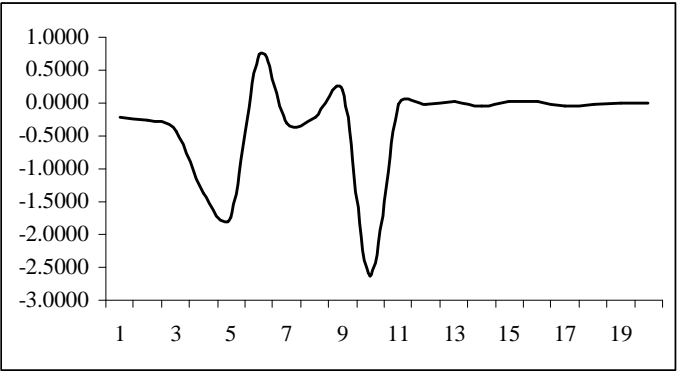

(d) Primary expediture

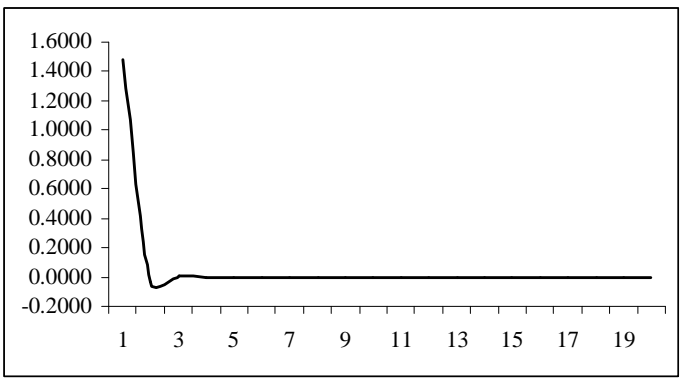

(f) Primary balance (solid), Total budget (dotted)

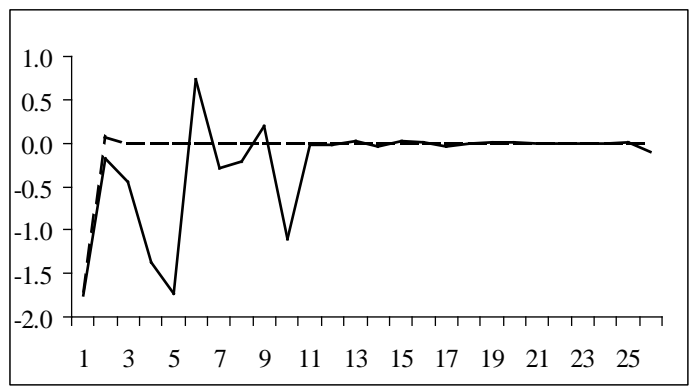


Figure 3. Germany. Responses (percent deviations from baseline values) to a temporary negative $1 \%$ multiplicative shock to the GDP growth gap.

(a) GDP growth gap

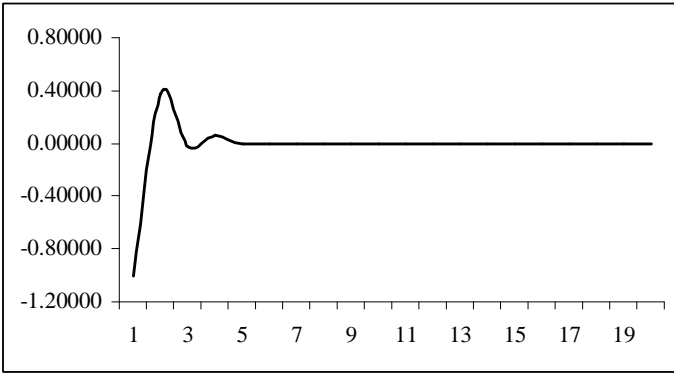

(c) Nominal (dotted) and current real interest rate (solid)

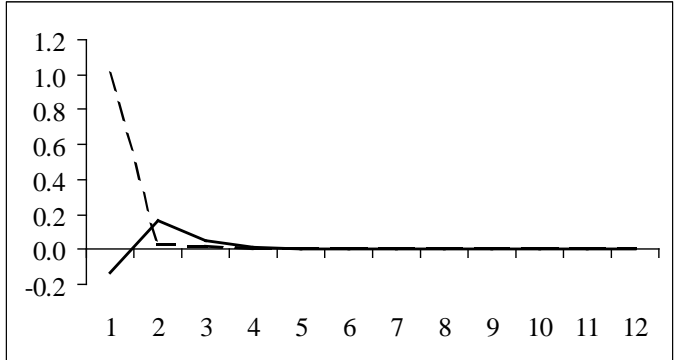

(e) Tax revenues

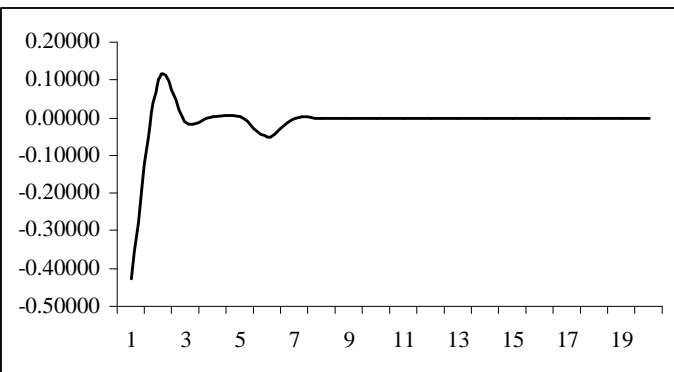

(b) Inflation

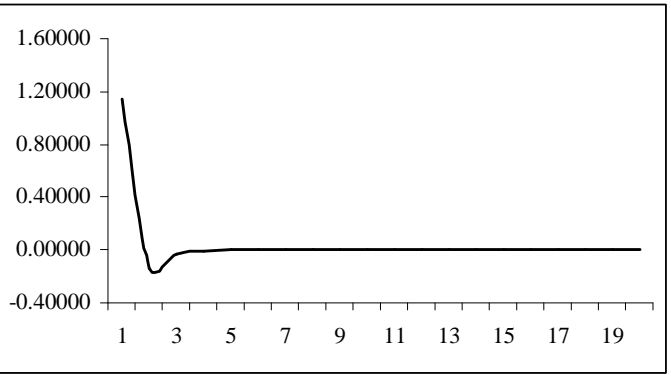

(d) Primary expediture

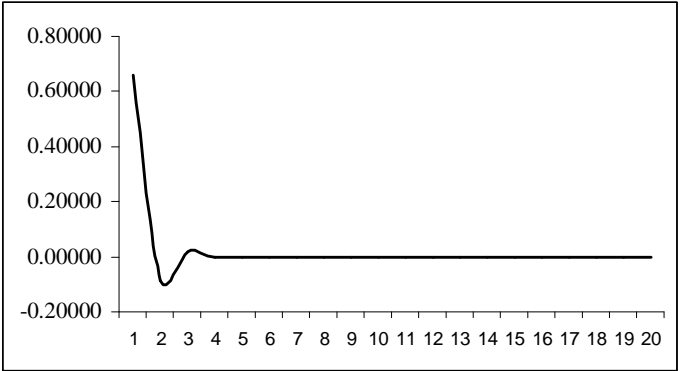

(f) Primary balance (solid), Total budget (dotted)

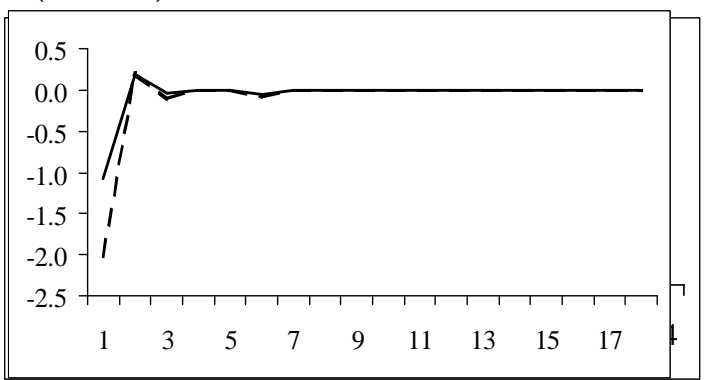


Elenco dei papers del Dipartimento di Economia

2000.1 A two-sector model of the effects of wage compression on unemployment and industry distribution of employment, by Luigi Bonatti

2000.2 From Kuwait to Kosovo: What have we learned? Reflections on globalization and peace, by Roberto Tamborini

2000.3 Metodo e valutazione in economia. Dall'apriorismo a Friedman, by Matteo Motterlini

2000.4 Under tertiarisation and unemployment. by Maurizio Pugno

2001.1 Growth and Monetary Rules in a Model with Competitive Labor Markets, by Luigi Bonatti.

2001.2 Profit Versus Non-Profit Firms in the Service Sector: an Analysis of the Employment and Welfare Implications, by Luigi Bonatti, Carlo Borzaga and Luigi Mittone.

2001.3 Statistical Economic Approach to Mixed Stock-Flows Dynamic Models in Macroeconomics, by Bernardo Maggi and Giuseppe Espa.

2001.4 The monetary transmission mechanism in Italy: The credit channel and a missing ring, by Riccardo Fiorentini and Roberto Tamborini.

2001.5 Vat evasion: an experimental approach, by Luigi Mittone

2001.6 Decomposability and Modularity of Economic Interactions, by Luigi Marengo, Corrado Pasquali and Marco Valente.

2001.7 Unbalanced Growth and Women's Homework, by Maurizio Pugno

2002.1 The Underground Economy and the Underdevelopment Trap, by Maria Rosaria Carillo and Maurizio Pugno.

2002.2 Interregional Income Redistribution and Convergence in a Model with Perfect Capital Mobility and Unionized Labor Markets, by Luigi Bonatti.

2002.3 Firms' bankruptcy and turnover in a macroeconomy, by Marco Bee, Giuseppe Espa and Roberto Tamborini.

2002.4 One "monetary giant" with many "fiscal dwarfs": the efficiency of macroeconomic stabilization policies in the European Monetary Union, by Roberto Tamborini.

2002.5 The Boom that never was? Latin American Loans in London 18221825, by Giorgio Fodor. 
2002.6 L'economia senza banditore di Axel Leijonhufoud: le 'forze oscure del tempo e dell'ignoranza' e la complessità del coordinamento, by Elisabetta De Antoni.

2002.7 Why is Trade between the European Union and the Transition Economies Vertical?, by Hubert Gabrisch and Maria Luigia Segnana.

2003.1 The service paradox and endogenous economic gorwth, by Maurizio Pugno.

2003.2 Mappe di probabilità di sito archeologico: un passo avanti, di Giuseppe Espa, Roberto Benedetti, Anna De Meo e Salvatore Espa.

(Probability maps of archaeological site location: one step beyond, by Giuseppe Espa, Roberto Benedetti, Anna De Meo and Salvatore Espa).

2003.3 The Long Swings in Economic Understianding, by Axel Leijonhufvud.

2003.4 Dinamica strutturale e occupazione nei servizi, di Giulia Felice.

2003.5 The Desirable Organizational Structure for Evolutionary Firms in Static Landscapes, by Nicolás Garrido.

2003.6 The Financial Markets and Wealth Effects on Consumption An Experimental Analysis, by Matteo Ploner.

2003.7 Essays on Computable Economics, Methodology and the Philosophy of Science, by Kumaraswamy Velupillai.

2003.8 Economics and the Complexity Vision: Chimerical Partners or Elysian Adventurers?, by Kumaraswamy Velupillai.

2003.9 Contratto d'area cooperativo contro il rischio sistemico di produzione in agricoltura, di Luciano Pilati e Vasco Boatto.

2003.10 Il contratto della docenza universitaria. Un problema multi-tasking, di Roberto Tamborini.

2004.1 Razionalità e motivazioni affettive: nuove idee dalla neurobiologia e psichiatria per la teoria economica? di Maurizio Pugno.

(Rationality and affective motivations: new ideas from neurobiology and psychiatry for economic theory? by Maurizio Pugno.

2004.2 The economic consequences of Mr. G. W. Bush's foreign policy. Can th US afford it? by Roberto Tamborini

2004.3 Fighting Poverty as a Worldwide Goal by Rubens Ricupero

2004.4 Commodity Prices and Debt Sustainability by Christopher L. Gilbert and Alexandra Tabova 
2004.5 A Primer on the Tools and Concepts of Computable Economics by K. Vela Velupillai

2004.6 The Unreasonable Ineffectiveness of Mathematics in Economics by Vela K. Velupillai

2004.7 Hicksian Visions and Vignettes on (Non-Linear) Trade Cycle Theories by Vela K. Velupillai

2004.8 Trade, inequality and pro-poor growth: Two perspectives, one message? By Gabriella Berloffa and Maria Luigia Segnana

2004.9 Worker involvement in entrepreneurial nonprofit organizations. Toward a new assessment of workers? Perceived satisfaction and fairness by Carlo Borzaga and Ermanno Tortia.

2004.10 A Social Contract Account for CSR as Extended Model of Corporate Governance (Part I): Rational Bargaining and Justification by Lorenzo Sacconi

2004.11 A Social Contract Account for CSR as Extended Model of Corporate Governance (Part II): Compliance, Reputation and Reciprocity by Lorenzo Sacconi

2004.12 A Fuzzy Logic and Default Reasoning Model of Social Norm and Equilibrium Selection in Games under Unforeseen Contingencies by Lorenzo Sacconi and Stefano Moretti

2004.13 The Constitution of the Not-For-Profit Organisation: Reciprocal Conformity to Morality by Gianluca Grimalda and Lorenzo Sacconi

2005.1 The happiness paradox: a formal explanation from psycho-economics by Maurizio Pugno

2005.2 Euro Bonds: in Search of Financial Spillovers by Stefano Schiavo

2005.3 On Maximum Likelihood Estimation of Operational Loss Distributions by Marco Bee

2005.4 An enclave-led model growth: the structural problem of informality persistence in Latin America by Mario Cimoli, Annalisa Primi and Maurizio Pugno

2005.5 A tree-based approach to forming strata in multipurpose business surveys, Roberto Benedetti, Giuseppe Espa and Giovanni Lafratta.

2005.6 Price Discovery in the Aluminium Market by Isabel FiguerolaFerretti and Christopher L. Gilbert. 
2005.7 How is Futures Trading Affected by the Move to a Computerized Trading System? Lessons from the LIFFE FTSE 100 Contract by Christopher L. Gilbert and Herbert A. Rijken.

2005.8 Can We Link Concessional Debt Service to Commodity Prices? By Christopher L. Gilbert and Alexandra Tabova

2005.9 On the feasibility and desirability of GDP-indexed concessional lending by Alexandra Tabova.

2005.10 Un modello finanziario di breve periodo per il settore statale italiano: l'analisi relativa al contesto pre-unione monetaria by Bernardo Maggi e Giuseppe Espa.

2005.11 Why does money matter? A structural analysis of monetary policy, credit and aggregate supply effects in Italy, Giuliana Passamani and Roberto Tamborini.

2005.12 Conformity and Reciprocity in the "Exclusion Game": an Experimental Investigation by Lorenzo Sacconi and Marco Faillo.

2005.13 The Foundations of Computable General Equilibrium Theory, by K. Vela Velupillai.

2005.14 The Impossibility of an Effective Theory of Policy in a Complex Economy, by K. Vela Velupillai.

2005.15 Morishima's Nonlinear Model of the Cycle: Simplifications and Generalizations, by K. Vela Velupillai.

2005.16 Using and Producing Ideas in Computable Endogenous Growth, by K. Vela Velupillai.

2005.17 From Planning to Mature: on the Determinants of Open Source Take Off by Stefano Comino, Fabio M. Manenti and Maria Laura Parisi.

2005.18 Capabilities, the self, and well-being: a research in psychoeconomics, by Maurizio Pugno.

2005.19 Fiscal and monetary policy, unfortunate events, and the SGP arithmetics. Evidence from a growth-gap model, by Edoardo Gaffeo, Giuliana Passamani and Roberto Tamborini 
PUBBLICAZIONE REGISTRATA PRESSO IL TRIBUNALE DI TRENTO 